\title{
Familismo e juventude: notas sobre o trabalho com jovens na socioeducação
}

\author{
Familism and youth: notes about working with young people in socio-education
}

Bárbara Leite PEREIRA*

https://orcid.org/oooo-0002-5739-4384

\section{Claudio Henrique Miranda HORST ${ }^{* *}$ \\ https://orcid.org/oooo-0002-2226-4520}

\begin{abstract}
Resumo: O artigo objetiva refletir sobre a contraditória relação entre: Estado, política socioeducativa voltada para jovens entre 18 e 21 anos e família. Trata-se de reflexão construída a partir da sistematização da prática profissional e cotejada pela revisão de literatura. Destacam-se os limites do Estado brasileiro e as estratégias familistas voltadas a esse público. Por fim, conclui-se que as perspectivas que acolhem o público de jovens entre dezoito a vinte e um anos, sem família e cumpridores de medida socioeducativa se afunilam em um processo de descartabilidade humana: ora pela ausência de um elo familiar, ora pela ineficácia da ação estatal.

Palavras-chave: Socioeducação, Família, Juventude e Estado.
\end{abstract}

\begin{abstract}
The article reflects on the contradictory relationship between the state socio-educational policy, aimed at young people between 18 and 21 years, and the family. It is based on a systematization of professional practice and a comparative literature review. The limits of the Brazilian State and the family strategy aimed at the public stand out. Finally, it concludes that the intended audience, young people between the ages of eighteen and twenty-one, without a family, and who are complying with socio-educational measures, become funneled into situations in which they become disposable, sometimes due to the lack of a family bonds and sometimes due to ineffectiveness of state action.
\end{abstract}

Keywords: Socio-education. Family. Youth. State.

Submetido em: 8/2/2020. Revisado em: 3/4/2020. Aceito em: 18/1/2021.

\section{Introdução}

\begin{abstract}
"Meus meninos são o que você teceu. [...] Eu não quero viver assim, mastigar desilusão. Este abismo social requer atenção" (Criolo - Menino Mimado).
\end{abstract}

\begin{abstract}
*Assistente Social do Tribunal de Justiça do Espírito Santo. R. Emílio Ferreira da Silva, 135 - Santa Martha, Vitória - ES, 29043-210. Mestre em Política social pela Universidade Federal do Espírito Santo (UFES). Doutoranda em Serviço Social pela Universidade Federal do Rio de Janeiro. (UFRJ, Rio de Janeiro, Brasil). Av. Pasteur, no 250, Urca, Rio de Janeiro (RJ), CEP.: 21941-901. E-mail: barbarapereira@gmail.com.

${ }^{* *}$ Assistente Social. Doutor em Serviço Social. Professor do Departamento de Serviço Social da Universidade Federal de Ouro Preto. (UFOP, Ouro Preto, Brasil). Universidade Federal de Ouro Preto, Instituto de Ciências Sociais Aplicadas. Rua do Catete, $\mathrm{n}^{\circ}$ 166, Centro, Mariana (ES), CEP.: 35420-000. E-mail: claudiovasques1@hotmail.com. Commons Atribuição 4.0 Internacional (https://creativecommons.org/licenses/by/4.o/deed.pt_BR), que permite copiar e redistribuir o material em qualquer suporte ou formato, bem como adaptar, transformar e criar a partir deste material para qualquer fim, mesmo que comercial. O licenciante não pode revogar estes direitos desde que você respeite os termos da licença.
\end{abstract}

Argum., Vitória, v. 13, n. 1, p. 199-212, jan./abr. 2021. | ISSN 2176-9575 
$\mathrm{D}$ esde meados dos anos 1970, o capital experimenta uma crise, fundamentalmente estrutural (MÉSZÁROS, 2002), acompanhada de transformações em todo mundo, à medida que o capital monopolista se vê "[...] compelido a encontrar alternativas para a crise em que é engolfado" (NETTO, 1996, p. 90, grifos nossos). Nessa direção, Netto (1996) sinaliza que o capital monopolista se empenha em complicados reajustes, deflagrando, dessa forma, novas tensões e transformações societárias.

Tais transformações impactam, diretamente, a sociabilidade - em particular, pelo tema que pretendemos esboçar - o sistema judiciário, a família e a juventude. No plano do imediato, a reestruturação incide sobre os estratos da juventude, como força essencial de trabalho, a partir de vínculos precarizados e, majoritariamente, informal -considerando nossa particularidade de capitalismo dependente ${ }^{1}$. Agravando, ainda mais, se olharmos para a juventude negra que, além do processo de superexploração do trabalho, está submetida ao genocídio e ao não acesso à política de educação (SILVA; BOTELHO, 2016).

A leitura que pretendemos construir parte da análise da totalidade social e da realidade concreta para identificar os impactos na vida dos sujeitos 'tecidos' por essa realidade. Essa leitura permitirá enfrentar o conservadorismo, presente nas explicações em disputa acerca dos fundamentos 'desse abismo social'.

Em artigo publicado em seu antigo blog na página da Veja, o Liberal Rodrigo Constantino defendeu que o genocídio da juventude negra não está relacionado às dimensões de classe e raça - elementos estruturantes dessa sociabilidade - a qual esses jovens pertencem. Mas, sim, ao esgarçamento ético, vivido pelas famílias quando questiona: "essa perda de valores éticos não teria algum elo com a dissolução familiar?". O aumento da violência, nesse exemplo, seria uma nítida evidência da falta de estrutura no interior dessas famílias, o que evitaria que seus filhos cometessem atos violentos pelas ruas.

Na contramão dessa perspectiva, acreditamos que as transformações, em curso, não dizem respeito à estrutura/organização das famílias, dado que as mesmas sofrem os impactos das lutas de classes, do mundo do trabalho. Esses impactos, por sua vez, interferem diretamente no perfil demográfico das populações, na organização das cidades e rebate fortemente nas famílias.

Nesse sentido, dentre as estratégias para a saída da crise estão, em curso, contrarreformas e retrocessos em relação às parcas garantias de direitos, provocando um recuo civilizatório.

Face à crise crônica de superacumulação do capital e a recessão econômica que se agudiza entre 2015-2016, o que vislumbramos no período pós-golpe é a celeridade do ajuste fiscal, acompanhado de uma bruta deterioração das condições de vida e trabalho. O recuo civilizatório observado - expresso nos índices alarmantes de desemprego, o retorno do Brasil ao mapa da fome e uma crise sanitária - sinaliza para a ruptura com o 'pacto social' inscrito na Constituição de 1988. Em detrimento dos direitos sociais e qualquer concessão aos 'de baixo' aplica-se um programa de devastação social, justificável numa tônica conservadora e de intensa criminalização da pobreza (SOUZA; SOARES, 2019, p. 13).

\footnotetext{
${ }^{1}$ Partimos do entendimento de que, na América Latina, a dinâmica da acumulação capitalista mundialmente forjou um capitalismo sui generis, no sentido das particularidades instituídas nas relações capital $x$ trabalho na região, conforme aponta Marini (2017). Tal dinâmica engendra o imperialismo e a dependência como duas faces de uma mesma moeda.
}

Argum., Vitória, v. 13, n. 1, p. 199-212, jan./abr. 2021. | ISSN 2176-9575 
Diante desse cenário, no centro do debate - a nosso ver em caráter acentuado - (re) colocase algumas questões: quem cobre as insuficiências das políticas públicas? Como ficam os jovens em conflito com a lei que não possuem vínculos familiares?

As premissas que envolvem o sujeito, em um contexto de intensas expressões da questão social $^{2}$, trazem demandas desproporcionais de responsabilização familiar, quando o objeto é a infância e a juventude. As políticas protetivas e/ou punitivas trazem brechas de intervenções públicas que ratificam um direcionamento estatal distante da complexidade de uma perspectiva totalizadora, própria desta fase de desenvolvimento da vida humana.

Subsidiadas pelas instituições da rede de atendimento, as limitações da ação estatal - ora pela escassez de recursos, ora pelo distanciamento de apreensão das necessidades objetivas e subjetivas dos sujeitos - remontam uma série de condutas que transmutam a perspectiva de um trabalho sólido, que garanta a reconstrução complexa da individualidade para um direcionamento efêmero e pontual do Estado 3 .

Um exemplo dessa pontuação é que, atualmente, existe uma lacuna dentro do sistema socioeducativo no Brasil: apesar do Estatuto da Criança e do Adolescente considerar excepcionalidade às pessoas entre dezoito e vinte e um anos de idade, a socioeducação atende a esse público ${ }^{4}$, entretanto, os adolescentes, ao completarem dezoito anos de idade, deixam de ser perfil da instituição de acolhimento e, em sua maioria, não possuem autonomia financeira e subjetiva para gerir uma vida independente. As políticas inclusivas de criação de casas repúblicas para esse público são escassas e pontuais, ou seja, não absorvem a demanda apresentada. Quando esses jovens possuem deficiência mental, as possibilidades de encaminhamento se tornam praticamente nulas.

Depreender as contradições presentes entre o Estado, a Política Social e as Famílias considerando o peso negativo que a ausência do suporte familiar entre os sujeitos que possuem idade entre dezoito e vinte e um anos assume no sistema de justiça - é o que nos movimenta nesta reflexão. Isso se faz necessário à medida que observamos uma série de contrarreformas das parcas políticas e dos compromissos públicos, assumidos historicamente, que reforçam elementos estruturais históricos da realidade brasileira que vão desde: a não inserção desse jovem em escola à dificuldade de construção de um projeto em conjunto com esse sujeito que lhe possibilite uma vida independente, nas dimensões objetiva e subjetiva.

\footnotetext{
${ }^{2}$ Nos termos de Netto (2011, p. 157): “[...] a "questão social” está elementarmente determinada pelo traço próprio e peculiar da relação capital/trabalho - a exploração. A exploração, todavia, apenas remete à determinação molecular da "questão social"; na sua integralidade, longe de qualquer unicausalidade, ela implica a intercorrência mediada de componentes históricos, políticos e culturais etc".

3Não há pretensões idealistas em apostarmos na possibilidade do Estado responder as necessidades humanas, ainda que, o tensionamento da luta de classes possa avançar em conquistas mínimas de direitos. Entendemos, de acordo com Mészáros, que: "[...] o Estado é parte integral das determinações estruturais do sistema do capital, e suas necessárias funções corretivas/solucionadoras só podem ser internas a ele. Assim, o Estado não pode eximir-se da crise estrutural em desdobramento do sistema do capital como um todo" (MÉSZÁROS, 2015, p. 94, grifos do autor).

4Art. $2^{\circ}$ Considera-se criança, para os efeitos desta Lei, a pessoa até doze anos de idade incompletos, e adolescente aquela entre doze e dezoito anos de idade. Parágrafo único. Nos casos expressos em lei, aplica-se excepcionalmente este Estatuto às pessoas entre dezoito e vinte e um anos de idade (BRASIL, 1990).
} 
Legitimados pela burocracia institucional, os equipamentos públicos saem a procura de um ente familiar ou de vinculação afetiva que passe a assumir o papel de cuidador deste jovem. Todavia, a postura incisiva por parte do Estado perpetua uma violação que passa despercebida e acrítica, à medida que pelas reiteradas tentativas, seguidas das inevitáveis negativas, reproduzem uma série de rejeições e abandonos afetivos, que, em suma maioria, não são trabalhadas de maneira individual com estes sujeitos.

Além disso, o direcionamento familista invisibiliza as falhas do Estado destinadas ao jovem durante todo o histórico de sua vida, sobretudo porque, ao se escudar neste trabalho de reinserção familiar, o que aparece em evidência é a ausência de família e não a incapacidade do Estado em prover: uma educação de qualidade, um trabalho de acompanhamento psicossocial e uma formação profissional qualificada.

Metodologicamente, o artigo foi construído baseado na sistematização da prática profissional junto as/ aos jovens e cotejada pela revisão de literatura. A fim de atingir os objetivos, o presente texto está organizado em dois momentos - além da presente introdução e dos apontamentos finais. O primeiro momento reflete sobre o familismo na particularidade sócio-histórica brasileira e sua incorporação como estratégia central no Brasil. No segundo momento, a ênfase recai sobre o impacto de tal tendência para as vidas dos jovens inseridos na socioeducação, donde apontamos questões para o trabalho junto aos mesmos.

\section{O familismo como estratégia central do Estado Brasileiro}

Nos mais diversos espaços de trabalho, a construção de respostas profissionais para as diversas demandas que surgem enxerga, nas próprias famílias atendidas, as estratégias para resolver seus 'problemas' e suas necessidades. Conforme aponta Iamamoto (2013), a referência na família para explicação da realidade é algo presente no exercício profissional, particularmente, das assistentes sociais.

[...], merece destaque a ênfase na formação social, moral e intelectual da família, considerada como célula básica da sociedade. Trata-se de um trabalho "educativo" entre a família operária, especialmente entre os mais carentes que têm acesso aos equipamentos socioassistenciais, com o objetivo de reforçar o núcleo familiar e integrar seus membros à sociedade. Buscam-se na história familiar os elementos explicativos de comportamentos individuais 'anômalos' ou 'desviantes' de um padrão tido como 'normal'. A família, como grupo social básico, é erigida como núcleo do trabalho profissional e como referência para a apreensão da vida em sociedade, em contrapartida às classes sociais (IAMAMOTO, 2013, p. 33).

Tal questão, longe de se tornar algo de responsabilidade apenas dos diversos profissionais o que nos levaria a uma leitura moralista do trabalho profissional - nos remete a mediações mais amplas. Nesse sentido, para compreendermos os fundamentos do familismo, partiremos de três elementos centrais que, a nosso ver, o caracterizam: a) a importância da família para o sistema do capital; b) a formação sócio-histórica brasileira; c) o avanço do (neo) conservadorismo expresso na centralidade ocupada pela família na política social.

Inicialmente, cabe destacar a importância da família para o sistema do capital. MÉSZÁROS, (2002, p. 272) nos alerta: 
A família está entrelaçada às outras instituições a serviço da reprodução do sistema dominante de valores, ocupando uma posição essencial em relação a elas, entre as quais estão as igrejas e as instituições de educação formal da sociedade. Tanto isso é verdade que, quando há grandes dificuldades e perturbações no processo de reprodução, manifesta de maneira dramática também no nível do sistema geral de valores - como a crescente onda de crimes, por exemplo -, os porta-vozes do capital na política e no mundo empresarial procuram lançar sobre a família o peso da responsabilidade pelas falhas e 'disfunções' cada vez mais frequentes, pregando de todos os púlpitos disponíveis a necessidade de 'retornar os valores da família tradicional' e aos 'valores básicos'. Às vezes tentam encerrar essa necessidade até mesmo na forma de leis quixotescas, procurando jogar nos ombros dos pais [...] a responsabilidade pelo 'comportamento antissocial' dos filhos [...] (MÉSZÁROS, 2002, p. 272).

Isso porque a reciprocidade dialética exige que a família participe das funções gerais da sociabilidade, que não incluem, somente, a reprodução biológica da espécie e a transmissão da propriedade privada. Mas exigem, também, “[...] a reprodução do sistema de valores da ordem dominante" (MÉSZÁROS, 2002, p. 272, grifos nossos). Neste interim cabe, particularmente, destacar a transmissão das leis do Estado via família, o qual prevê que tais indivíduos - jovens - se comportem conforme a moral dominante. Nesse sentido, independente do modelo da organização familiar, o aspecto central da instituição família hoje:

[...] é a perpetuação - e a internalização - do sistema de valores profundamente iníquo, que não permite contestar a autoridade do capital, que determina o que pode ser considerado um rumo aceitável de ação dos indivíduos que querem ser aceitos como normais, em vez de desqualificados por 'comportamento não conformista' (MÉSZÁROS, 2002, p. 271, grifos nossos).

Os conservadores compreendem a família como a base moral da sociedade, base pela qual se transmite valores e tradição. Consideram, ainda, que é por meio da estabilidade social das famílias, e do seu papel econômico, que elas contribuem para a eternização da sociedade e do seu modo de organização (ESCORSIM NETTO, 2011).

Contudo, a importância que a instituição família assume para o sistema do capital possui particularidade em nossa formação sócio-histórica, principalmente se tomarmos como ponto de partida a importância que a família ocupou no plano da reprodução social desde o colonialismo. No caso brasileiro, a realidade foi edificada em uma estrutura historicamente centralizada em relações servis, oligárquicas, cuja herança escravista demarca uma formação social em que os direitos são amplamente tratados com viés assistencialista, paternalista, clientelista e largamente centrado nas famílias.

Alencar (2011) descreve que "[...] a família se constituiu no país em uma espécie de garantia ética, moral e material" (ALENCAR, 2011, p. 136). Nessa lógica, a destituição/ausência dos direitos resulta, na maioria dos casos, em despolitização de significativas dimensões da vida social, na qual "[...] as necessidades sociais são tratadas como verdadeiros dramas da vida privada, de forma despolitizada, quando na verdade se trata de questões de ordem pública [...]" (ALENCAR, 2011, p. 136, grifos nossos).

Dessa forma, conforme destaca Iamamoto (2001), "[...] fazer do interesse privado a medida de todas as coisas, obstruindo a esfera pública, a dimensão ética da vida social [...]" (IAMAMOTO, 2001, p. 37) é próprio do traço conservador persistente na realidade brasileira.

Argum., Vitória, v. 13, n. 1, p. 199-212, jan./abr. 2021. | ISSN 2176-9575 
Essa coexistência de temporalidades históricas desiguais, apontada pela autora, faz com que a "questão social" apresente tanto as marcas do passado quanto do presente, radicalizandoas.

Alencar (2011) sinaliza, ainda: "[...] entendia-se que, por meio da família, o Estado chegava ao homem e este ao Estado, e nesse sentido, uma vida familiar ordenada e disciplinada passou a ser o alvo de práticas sociais diversas, de médicos, de juristas, de filantropos e, sobretudo, do Estado brasileiro" (ALENCAR, 2011, p. 137). O resultado histórico da estratégia de responsabilização das famílias está inserida em um contexto com particularidades de um sistema capitalista, cujo agravamento das condições de sobrevivência se somam às dificuldades estruturais de um país dependente. Ao pensarmos a força de trabalho como superexplorada e, ao mesmo tempo, que as famílias não acessam a um sistema de proteção social público e universal, as mesmas são sobrecarregadas com funções que não são capazes de arcar.

Apresentada a importância de tal instituição para o sistema do capital e para a formação social brasileira, cabe apontar, por fim, o reforço, no tempo presente, da tendência familista na política social brasileira. Segundo Mioto (2010):

A ideia central da proposta familista reside na afirmação da tradição secular que existem dois canais naturais para satisfação das necessidades dos indivíduos: a família e o mercado. Somente quando esses falham é que interferência pública deve acontecer e, de maneira transitória. Então a ideia que vem embutida no campo da incorporação da família na política social é a ideia de falência da família. Ou seja, a política pública acontece prioritariamente, de forma compensatória e temporária, em decorrência da sua falência no provimento de condições materiais e imateriais de sobrevivência, de suporte afetivo e de socialização de seus membros. Isso corresponde a uma menor provisão de bem-estar por parte do Estado. $\mathrm{O}$ fracasso das famílias é entendido como resultado da incapacidade de gerirem e otimizarem seus recursos, de desenvolverem adequadas estratégias de sobrevivência e de convivência, de mudar comportamentos e estilos de vida, de se articularem em redes de solidariedade e também de serem incapazes de se capacitarem para cumprir com as obrigações familiares (MIOTO, 2010, p. 169).

Desde os anos 1990, a centralidade da família passou a ser, formalmente, materializada nas políticas sociais. No entanto, não é a demarcação formal do familismo, via política social, no Brasil, que a nosso ver deve ser tratada como o surgimento de tal fenômeno e, sim, a formalização na política social. Esse marco é uma expressão histórica do lugar da família na sociabilidade burguesa e, particularmente, da tendência familista que estruturou a sociedade brasileira (HORST, 2018).

Na particularidade brasileira, a família sempre foi instância central na configuração da proteção social e referência na estruturação das políticas. Nesse sentido, o familismo é entendido como um padrão de inter-relação reinante na sociedade, isso porque, macrossocialmente - ao tornar-se a família um microcosmo necessário - e considerando nossa formação histórica, a mesma assume centralidade na organização dos sistemas de proteção social, sendo considerada como instituição central provedora de bem-estar. Nessa direção, cabe destacar a rede de mulheres (mães, avós, vizinhas) que respondem pelo trabalho familiar, especialmente pelo cuidado dos dependentes (MIOTO et al., 2015; HORST; MIOTO, 2017).

Argum., Vitória, v. 13, n. 1, p. 199-212, jan./abr. 2021. | ISSN 2176-9575 
O familismo, como um mecanismo de dominação ideológica, se reproduz como estratégia para responsabilizar os indivíduos e suas famílias pelo caos instalado pela sociabilidade burguesa. As determinações do neoconservadorismo contribuem para o mascaramento dos determinantes e fundamentos do sistema do capital e suas crises; deslocam as questões, que somente coletivamente poderão ser resolvidas, para o âmbito 'particular'; e centralizam as famílias como naturalmente responsáveis pelos seus membros e, no interior destas, constroem o apassivamento dos sujeitos, a produção de consensos, já que se trata de um problema da minha família e não da sociabilidade burguesa.

Por fim, antes de avançarmos nas reflexões em torno da estratégia equivocada do Estado particularmente no judiciário - da busca incessante por familiares dos jovens em conflito com a lei cabe um último destaque.

Não desconsideramos o lugar incontestável da família para os indivíduos e para a reprodução do ser social. Por isso, reconhecemos a importância - diante da particularidade de algumas situações concretas - junto a elas. Se tratando de adolescentes e jovens na periferia do capitalismo, os mesmos "[...] necessita [m] de uma institucionalidade para obter proteção e socialização em fases mais sensíveis da vida, uma vez que não teria condições socioeconômicas para uma autoconstrução absoluta do seu estilo de vida" (MACHADO, 2018, p. 528). No entanto, reconhecer tais dimensões e importância não significa reproduzir o entendimento de tal instituição, apenas, como central e fundante da sociedade.

Reconhecer a importância da família como esfera privada das relações sociais, [...] não é pretexto para sua supervalorização, ou entificação, ou seja, sua pseudoafirmação como sujeito, vez que efetivamente isso é uma impossibilidade. Tal percurso equívoco, além de encobrir as contradições do processo de pauperização, tem submetido as famílias a uma solitária e contraditória condição de protagonista social, cuja proteção de seus membros deve ser asseguradas sob auspícios dos serviços socioassistenciais. Mas não só a proteção, sobretudo, cabe a esse fantasmático ente a tarefa de sair da pobreza (PAIVA; CARRARO; ROCHA, 2014, p. $41)$.

Portanto, a família deve ser entendida a partir de sua contraditoriedade, ou seja:

É na própria reprodução social que localizamos a família - compreendendo-a enquanto resultado do desenvolvimento das necessidades do ser social, consequência do processo de sociabilidade. Portanto, a família ocupa um lugar 'natural' de cuidado, proteção, sobrevivência - que possibilitou o desenvolvimento histórico do 'sentimento de família'. No entanto, a divisão social do trabalho e a propriedade privada dos meios de produção colocaram em xeque esse lugar da família na era do capital. Não sendo possível compreendê-la somente em torno de sua 'natureza' (com vistas a naturalizá-la na perspectiva positivista e/ou divina), nem somente em torno da sua particularidade no capital (com vistas a eternizá-la), mas apenas na sua contraditoriedade (HORST, 2018, p.78).

A contradição da qual a instituição família é constituída e constituinte no sistema do capital deve ser compreendida a partir de seus aspectos e elementos contrários que são interrelacionados. Nesse sentido, podemos reafirmar a necessidade de desvendarmos tais elementos que a constituem para além de uma leitura maniqueísta que considere a família como boa ou má; ou, naturalmente, responsável pelos seus membros.

Argum., Vitória, v. 13, n. 1, p. 199-212, jan./abr. 2021. | ISSN 2176-9575 


\section{Familismo, Judiciário e o impacto na vida dos jovens}

O processo de responsabilização da família por encargos dentro do sistema de proteção social, presente na configuração e na condução da política social brasileira contemporânea, se insere no debate sobre uma velha questão que é: a forma de incorporação das famílias nas estratégias de proteção social através das políticas públicas.

Os serviços disponíveis para os jovens entre dezoito e vinte e um anos, que não possuem família para direcionamento, disponibilizados na área da política de assistência social, são: casas repúblicas, aluguel social, abrigo para adultos e, por fim, inserção no mercado de trabalho. Quando o adolescente possui alguma deficiência mental, o encaminhamento acontece pela via da saúde, através das residências inclusivas e terapêuticas, especificamente.

Ocorre que o aluguel social, as casas repúblicas e os abrigos para adultos são, majoritariamente, municipalizados, o que dificulta uma mobilidade de um adolescente caso não venha, originalmente, do município que oferte o serviço. Além disso, os abrigos para adultos possuem caráter provisório, na mesma busca de reinserção familiar, reproduzida pela primeira infância e problematizada neste artigo.

Quando os jovens possuem alguma deficiência mental, as problemáticas se equiparam e acrescenta-se o fato das exigências de especificidades das doenças para inserção nas políticas de saúde. Por exemplo, as residências terapêuticas “[...] são casas localizadas no espaço urbano, constituídas para responder às necessidades de moradia de pessoas com transtornos mentais graves, institucionalizadas ou não" (BRASIL, 2004, p. 6, grifos nossos). Por isso, os encaminhamentos seguem uma série de exigências como laudos e análise criteriosa por parte de uma equipe técnica responsável, que não correspondem ao perfil dos jovens destacados neste artigo - de 18 a 21 anos sem familiares. Bem como não equivale ao fluxo institucional de uma unidade de atendimento.

Por último, haveria a possibilidade de se trabalhar com este jovem sua independência de forma prioritária, tão cedo se verificasse a impossibilidade de inserção familiar. Mas o que se observa são reiteradas tentativas, por parte do Estado, de uma busca incansável por um alguém que se responsabilize, seja pela vinculação sanguínea, seja pela via adotiva, socioafetiva. Nessa direção, poderíamos apontar que a face familista do sistema judiciário persiste - frente às parcas políticas sociais - no entendimento que: diante da ausência da família, qual a garantia que tais jovens estarão em conformidade com a ordem e os valores dominantes estabelecidos?

No campo da moral dominante, parte-se do pressuposto da existência de uma 'normalidade familiar' - até mesmo da exaltação dessa possível normalidade - e, por isso, o repúdio aos comportamentos e às atitudes, que dentro de certos parâmetros não é 'aceito' e 'correto'. Quando nos referimos aos adolescentes e aos jovens - particularmente daqueles em conflito com a lei - é comum o preconceito familiar concomitante ao julgamento das famílias dos jovens, compreendidas como modelos familiares que não correspondem à 'normalidade' ou são 'desestruturados'. 
Costa e Goldani (2015) discorrem que o preconceito familiar é utilizado nos espaços do judiciário - particularmente, quando se refere ao tratamento penal de adolescentes e jovens - como estratégias e justificativas para intervenções nas famílias. Ou seja, trata-se da busca incessante por familiares que possivelmente garantirão a manutenção dos padrões de moralidade socialmente aceitos. Nesse sentido, "[...] a imposição desses padrões morais a família que não os adotam funciona como parte de uma estratégia de dominação das classes dominantes sobre as classes pobres" (COSTA; GOLDANI, 2015, p. 91).

Na contramão de uma leitura moralista, que concebe a família como referência para leitura da realidade, há um cenário concreto que expressa a condição de exploração/opressão do sistema do capital, principalmente quando observado a partir das condições de vida da juventude negra periférica:

\begin{abstract}
Hoje, estamos diante de um genocídio de jovens pobres e negros, que morrem e matam em um enfrentamento autofágico e fratricida, sem quartel, sem bandeira e sem razão. Apesar de a maioria resistir, muitos jovens sem perspectiva e esperança, distantes das oportunidades geradas pela educação e a cultura, sem lazer, esporte, afeto, reconhecimento e valorização, com suas auto-estimas degradadas, acabam cedendo à sedução exercida pelo crime. Ao se deixarem recrutar, aceitam a arma como o passaporte para a visibilidade social e o reconhecimento, antes de usá-la em benefício de estratégias econômicas. A fome de significado e valorização é mais funda e mais radical que a fome física. A cooptação pelo crime é mais que uma operação meramente contábil. Não se trata apenas de saber quem dá mais, mas qual a natureza daquilo que se recebe e que função o bem visado pode cumprir, no imaginário e no mundo afetivo dos jovens guerreiros. Recrutados, organizam-se em torno de núcleos armados de poder que cultivam os valores da guerra (SOARES; GUINDANI, 2007, p. 4).
\end{abstract}

Em outras palavras, com a janela laboral oportunizada pelo tráfico de drogas, encontramos jovens que, nos subterfúgios de sustentar o mercado das drogas, vislumbram-se no crime e o crime neles vislumbra, a tessitura para sobreviver às imposições de consumo. Esse encontro entre o extremo da formalidade, exemplificada pelas condições de trabalho vivenciadas pelos magistrados, e o oposto de seu eixo, naturalizada na informalidade desse ofício informal e ilegal de substâncias psicoativas, cruzam-se: no capitalismo, no Poder Judiciário.

A alternativa utilizada, para atender a essa demanda, na maioria das vezes, sob o manto da pseudo proteção social e garantia de direitos, é a evocação das famílias sob qualquer pretexto para atingir os objetivos da justiça: tanto nos casos que a família existe e possui vínculos afetivos de fato; como também, quando não possuem família e a decisão só é tomada a partir da vinculação do adolescente com parentes e/ou familiares distantes.

O pressuposto é o mesmo em ambos os casos: a família é a instituição capaz de impor ao jovem em conflito com a lei e desprotegido pelo Estado controle e imposição dos valores dominantes. No entanto, “[...] a culpabilização das famílias acaba por se revelar uma falácia criada ao longo das décadas para justificar a ausência do Estado no campo social em apoio às famílias quando enfrentam dificuldades no cuidado com seus filhos e, paralelamente, sua interferência controladora na vida privada das classes populares" (COSTA; GOLDANI, 2015, p. 94). 
A valorização da família, constante nos conservadores, está conectada a um traço distintivo do pensamento conservador: a defesa da constituição de grupos intermediários, capazes de junto com a família - mediar a relação entre os indivíduos e a sociedade. "Tais grupos associações, corporações [...] - são, igualmente, a única garantia para assegurar a harmonia orgânica da sociedade, provendo os vínculos de solidariedade e coibindo as tendências sociais dispersivas; [...]” (ESCORSIM NETTO, 2011, p. 66).

Conforme identificamos, existe uma quantidade significativa de casos na socioeducação de adolescentes/jovens sem família, ficando os mesmos sem visitas e sem um acompanhamento regular. Nessas circunstâncias, os direcionamentos adotados são de tentativas reiteradas pela procura de uma parentela que acolha o socioeducando quando do desligamento das unidades de internação, mesmo quando esse jovem passou toda a medida sem uma presença que o referenciasse. Algumas dessas situações sequer consideram a vinculação afetiva, forçando um suporte familiar pela via sanguínea.

Ao apreender uma reintegração familiar nesses moldes, o Poder Judiciário se respalda em uma aceitação moral de condução: o adolescente/jovem fora entregue a um familiar, acreditando-se no cumprimento da função institucional em sua completude. Entretanto, não se leva em consideração a violência institucional reproduzida, tampouco como será a relação cotidiana do sujeito junto a essa terceira pessoa, o que repercute em uma série de complexidades desconsideradas no decorrer processual.

Paralelo a isso, não se pode deixar de mencionar o ambiente dinâmico, tensionado e exigente, que é atuar em uma unidade de internação, que assevera dos profissionais uma imersão técnica sobrecarregada que carece de suporte institucional: tanto de caráter psicológico, como de saúde emocional.

Cabe ressaltar, de maneira contraditória, que o trabalho na socioeducação pela esfera executiva, quando busca construir alternativas à tendência familista, também encontra desafios de caráter objetivo, quais sejam: fragilidade nos encaminhamentos para a rede socioassistencial que a cada dia está com uma quantidade mínima de profissionais para atender uma demanda crescente de usuários em equipamentos com infraestrutura precária e recursos reduzidos. Além disso, em grande parte, os socioeducandos possuem baixa escolaridade e ínfimas possibilidades de inserção no mercado de trabalho.

No entanto, diante da ausência de respostas públicas, apostamos que o trabalho, junto a esse público, deve priorizar em seus instrumentais, tais como: na elaboração de estudos sociais, laudos e pareceres - a totalidade social. Nesse sentido, deve refletir sobre a tendência da proteção social - ou ausência dela - na vida dos jovens. Tal posicionamento, a nosso ver, impossibilita que ante a ausência de um sistema público de proteção social, que o trabalho não resulte na culpabilização das famílias, responsabilizando-as pelas mazelas da realidade. Por isso, a aposta na necessidade de construirmos respostas alternativas de vinculações com os sujeitos seja: através de articulações comunitárias, grupos, movimentos sociais sejam por vias artísticas. 


\section{Reflexões finais}

Em momentos de acirramento da crise estrutural do capital, uma das estratégias é o reforço e o chamamento de instituições como a família. Conforme aponta Barroco (2017), "[...] as crises sociais são concebidas pelos conservadores como decorrências de uma crise moral, porque consideram que a sociabilidade e a política são fundadas pela ordem moral" (BARROCO, 2017, p. 41).

Porém, consideramos que é próprio da 'dialética da juventude' tal como discorre Groppo (2004, p. 21, grifos nossos), "[...] a possibilidade dos indivíduos e grupos jovens desenvolverem, de modo autônomo, identidades e valores próprios, relativamente ou muito destoantes dos padrões sociais de seu tempo". Nesse sentido, a face familista do sistema judiciário é apontada, neste artigo, como mais uma das estratégias de mascaramento das contradições inerentes à sociabilidade. Por isso, a estratégia familista, afinal,

A existência de uma família que permitisse à geração mais jovem pensar em seu papel futuro na vida em termos de um sistema de valores alternativos - realmente igualitário -, cultivando o espírito de rebeldia potencial em relação às formas existentes de subordinação, seria uma completa infâmia do ponto de vista do capital (MÉSZÁROS, 2002, p. 271).

Há um comparecimento de uma política punitiva, que infringe uma parcela da população com suas determinações de classe e raça, caracterizados por elementos históricos de desigualdades e das contradições próprias do sistema capitalista. Sendo assim, o Estado apresenta uma resposta social de punibilidade, ao passo que o jovem cumprirá, com seu tempo, uma medida de internação. Contudo, paralelamente, o Estado não envida esforços para garantir um acolhimento das demandas desse sujeito na esfera protetiva, quando da desvinculação institucional com a política socioeducativa.

Portanto, as perspectivas que acolhem ao público de jovens entre dezoito a vinte e um anos, sem família e cumpridores de medida socioeducativa, afunilam-se em um processo de descartabilidade humana: ora pela ausência de um elo familiar; ora pela ineficácia da ação estatal no acolhimento das demandas desse sujeito. A partir disso, observamos uma intensificação da fragilidade de atuação do Estado em suas instituições, decorrente da impossibilidade de direcionar a atenção focalizada na família, o que acarreta uma série de ações deficitárias, desconexas das complexidades que engendram este público.

O contexto apresentado impulsiona a necessidade de acolher referências que ultrapassem o ciclo institucional e agregue, a este sujeito, outras perspectivas de vinculação.

A etapa da juventude corresponde a um período da vida em que o ser encontra-se na fase de transição ao mundo adulto. Sua vida cotidiana é repleta de novidades, de sonhos, de perspectivas de um futuro a ser conquistado. Os referentes, como família, instituições, grupos de jovens, movimentos sociais, etc., podem desempenhar um papel importante para a formação dos conteúdos que permitem a esse jovem fazer as escolhas que podem tornar-lhe um adulto melhor. É nesse período que o trabalho e a educação são excepcionais para os futuros desígnios na vida do jovem (MARTINS, 2016, p. 61). 
A partir dessas premissas, torna-se mister repensar as dinâmicas institucionais protagonizadas para esse público, tanto no aspecto institucional, como na própria perspectiva de ação profissional. Considerar as particularidades geradas pelo racismo estrutural $^{5}$ e pelas contradições intrínsecas ao processo capitalista de produção remonta uma perspectiva de trazer para esse jovem a (re) significação da família e do Estado no exercício de sua história.

O fluxo discutido traduz uma ultrapassagem do esforço cotidiano de buscar uma família, para (re) criar sentidos que visibilizem, incluam e semeiem transformações dialeticamente individuais e coletivas. Assim, consideramos de suma importância um alinhamento entre as demandas apresentadas pelo jovem, quando do cumprimento de medida socioeducativa, com os serviços e ampliação dos equipamentos públicos para o acolhimento das perspectivas problematizadas neste artigo.

É preciso rever as rotinas adotadas para os adolescentes com saúde mental, no intuito de impedir o encarceramento dessa parcela da população, bem como repensar a produção documental nesses espaços, em âmbito geral, por meio do Plano Individual de Atendimento (PIA) e dos relatórios. Outra medida salutar é a extensão da medida protetiva até os 21 anos, uma vez que essa prerrogativa está garantida somente para o cumprimento de medida socioeducativa e a criação de protocolos que envolvam a rede socioassistencial, na busca por garantir e ampliar os serviços ofertados pelo Estado.

Embora alguns apontamentos e diretivas tenham sido mencionadas nesses tópicos, reafirmamos que a configuração do processo social de produção e reprodução da vida, só alcança o rompimento de sua estrutura como produto de homens e mulheres livremente socializados, quando se busca a liberdade na ruptura do capitalismo. Para isso - por questão de sobrevivência -, precisamos construir uma forma de sociabilidade que rompa, em definitivo, com a submissão diante a classe burguesa, que: além de direcionar as instituições do Estado, fragmentam a luta dos trabalhadores, segmentam a vida e colocam precocemente os adolescentes/jovens negros e pobres atrás das grades.

\section{Referências}

ALENCAR, M. M. T. Família, Trabalho e Reprodução Social: limites na realidade brasileira. In: DUARTE, Marco José de Oliveira; ALENCAR, Mônica Maria Torres de (Org.). Família e Famílias: práticas sociais e conversações contemporâneas. Rio de Janeiro: Lumen Juris, 2011.

BARROCO, M. L. S. Ética e Serviço Social. 5. ed. São Paulo: Cortez, 2017.

BRASIL. Estatuto da criança e do adolescente: Lei federal no 8069, de 13 de julho de 1990. Rio de Janeiro: Imprensa Oficial, 1990.

\footnotetext{
5 É impossível adentrar nesse debate sem trazer à tona a questão racial. Flauzina (2006) relata o não rompimento do sistema penal brasileiro com o passado colonial vivenciado no país "[...] o que arrasta vestígios contemporâneos de um direito penal de ordem privada, herdeiro de um estatuto escravocrata [...]" (FLAUZINA, 2006, p. 42) e complementa que "[...] embalado na cantiga da democracia racial, o Estado foi, pela precarização da vida do contingente negro, construindo as condições para o descarte do segmento" (FLAUZINA, 2006, p. 100).
}

Argum., Vitória, v. 13, n. 1, p. 199-212, jan./abr. 2021. | ISSN 2176-9575 
BRASIL. Ministério da Saúde. Residências Terapêuticas: pra quem precisa de cuidados em saúde mental, o melhor é viver em sociedade. Brasília (DF): Ministério da Saúde, 2004.

COSTA, A. P. M; GOLDANI, J. M. A Influência do Contexto Familiar nas Decisões Judiciais a Respeito de Atos Infracionais de Adolescentes: o intervencionismo familiar ainda se faz presente? Revista Textos \& Contextos, Porto Alegre, v. 14, n. 1, jan./jun.2015.

ESCORSIM NETTO, L. O conservadorismo clássico: elementos de caracterização e crítica. São Paulo: Cortez, 2011.

FLAUZINA, A. L. P. Corpo negro caído no chão: o sistema penal e projeto genocida do Estado brasileiro. 2006. Dissertação (Mestrado em Direito)-Faculdade de Direito da Universidade de Brasília, Brasília (DF), 2006.

GROPPO, L. A. Dialética das juventudes modernas e contemporâneas. Revista de Educação do Cogeime, Belo Horizonte, ano 13, n. 25, dez.2004.

HORST, C. H. M. Família, Marxismo e Serviço Social: Desvendando o Invólucro Místico. Tese (Doutorado em Serviço Social)- Centro Sócio Econômico, Programa de Pós-Graduação em Serviço Social da Universidade Federal de Santa Catarina, Florianópolis, 2018.

HORST, C. H. M.; MIOTO, R. C. T. Serviço Social e o trabalho com famílias: renovação e conservadorismo? Revista Em Pauta, Rio de Janeiro, n. 40, 2017.

IAMAMOTO, M. V. Renovação e Conservadorismo no Serviço Social: ensaios críticos. 12. ed. São Paulo: Cortez, 2013.

IAMAMOTO, M. V. A questão social no capitalismo. Temporalis, Brasília (DF): Associação Brasileiro de Ensino e Pesquisa em Serviço Social, ano 2, n. 3, 2001.

MACHADO, P. H. S. S. A condição juvenil periférica: notas introdutórias para entender a juventude no capitalismo dependente. Revista Brasileira de Estudos Latino-Americanos, Florianópolis, v. 8, n. 3, set./dez.2018.

MARINI, R. M. Subdesenvolvimento e Revolução. 6. ed. Florianópolis: Insular, 2017. (Coleção Pátria Grande).

MARTINS, J. C. Ser Jovem Trabalhador: entre a conformação à reprodução metabólica do capital e sua superação. 2016. Tese (Doutorado em Educação)-Programa de Pós-Graduação em Educação da Universidade Federal de Santa Catarina, Florianópolis, 2016.

MÉSZÁROS, I. A montanha que devemos conquistar: reflexões acerca do Estado. 1. Edição. São Paulo: Boitempo, 2015.

MÉSZÁROS, I. Para Além do Capital: rumo a uma teoria da transição. 1. reimp. São Paulo: Boitempo, 2002.

MIOTO, R. C. T. Família, Trabalho com Famílias e Serviço Social. SERV. SOC. REV., Londrina, v. 12, n. 2, p. 163-176, jan./jun.2010. 
MIOTO, R. C. T. et al. (Orgs.) Familismo, Direitos e Cidadania: contradições da política social. São Paulo: Cortez, 2015.

NETTO, J. P. Capitalismo Monopolista e Serviço Social. 8. ed. São Paulo: Cortez, 2011.

NETTO, J. P. Transformações societárias e Serviço Social: notas para uma análise prospectiva da profissão no Brasil. Serviço Social e Sociedade, São Paulo: Cortez, ano 17, n. 5o, abr. 1996.

PAIVA, B. A.; CARRARO, D.; ROCHA, M. Cartografia teórico-metodológica no estudo da proteção socioassistencial básica do SUAS. In: PAIVA, B. A. (Org.). Sistema Único de Assistência Social em perspectiva: direitos, políticas públicas e superexploração. São Paulo, Veras Editora, 2014.

SILVA, E. R. A; BOTELHO; R. U. Dimensões da Experiência Juvenil Brasileira e Novos Desafios às Políticas Públicas. Brasília : Ipea, 2016.Ver: http://www.ipea.gov.br/portal/images/stories/PDFs/livros/160513 livro dimensoes.pdf.

SOARES, L. E; GUINDANI, M. A Violência do Estado e da Sociedade no Brasil Contemporâneo. Nueva Sociedad, Buenos Aires, n. 208, Marzo-Abril, 2007.

SOUZA, G.; SOARES, M. Contrarreformas e recuo civilizatório: um breve balanço do Governo Temer. SER Social, Brasília (DF), v. 21, n. 44, p. 11-28, 13, mar. 2019.

Bárbara Leite PEREIRA Trabalhou na análise e interpretação dos dados, na redação do artigo e na aprovação da versão a ser publicada.

Assistente Social do Tribunal de Justiça do Espírito Santo. Mestre em Política social pela Universidade Federal do Espírito Santo (UFES). Doutoranda em Serviço Social pela Universidade Federal do Rio de Janeiro. (UFRJ, Rio de Janeiro, Brasil.

Claudio Henrique Miranda HORST Trabalhou na concepção e delineamento, na redação do artigo e na aprovação da versão a ser publicada.

Assistente Social. Professor no Departamento de Serviço Social da Universidade Federal de Ouro Preto. Doutor em Serviço Social pela UFSC. Mestre em Política Social pela UFES. Membro do Livre Hermana - Núcleo de Estudos e Pesquisas sobre Formação Social Latino-Americana e Brasileira 